Int. J. Electrochem. Sci., 14 (2019) 3443 - 3454

\title{
Synthesis, Crystal Structure and Corrosion Inhibition Effect of S-benzyl-O,O'-bis( $p$-tert-butyl phenyl)dithiophosphate for Q235 Steel in 1.0 M HCl
}

\author{
Chengduan Wang ${ }^{l}$, Wan Gou ${ }^{l}$, Changlu Liu ${ }^{1}$, Dong Fu ${ }^{l}$, Lvshan Zhou ${ }^{l}$, Chuan Lai, ${ }^{1,2 *}$ \\ Bin Xie ${ }^{2, *}$, Shasha Zhu ${ }^{2}$ \\ ${ }^{1}$ Eastern Sichuan Sub-center of National Engineering Research Center for Municipal Wastewater \\ Treatment and Reuse, Sichuan University of Arts and Science, Dazhou 635000, China \\ ${ }^{2}$ School of Materials Science and Engineering, Sichuan University of Science and Engineering, \\ Zigong 643000, China \\ *E-mail: 1aichuanemail@163.com; xiebinsuse@163.com
}

doi: $10.20964 / 2019.04 .50$

Received: 13 August 2018 / Accepted: 18 October 2018 / Published: 10 March 2019

The new corrosion inhibitor of S-benzyl-O,O'-bis( $p$-tert-butyl phenyl)dithiophosphate (SOBP) was synthesized and characterized by elemental analysis, FT-IR, ${ }^{1} \mathrm{H}$ NMR, ${ }^{13} \mathrm{C}$ NMR, ${ }^{31} \mathrm{P}$ NMR and single crystal X-ray diffraction. Meanwhile, the corrosion inhibition and mechanism of SOBP for Q235 steel in $1.0 \mathrm{M} \mathrm{HCl}$ were studied by weight loss and potentiodynamic polarization measurement, also the crystal structure of corrosion inhibitor was presented. The potentiodynamic polarization measurement result indicates that SOBP is a mixed-type inhibitor. The two methods all reveal that the inhibition efficiency increases with the concentration of SOBP, which is an effective corrosion inhibitor. The adsorption of SOBP on Q235 steel surface in $1.0 \mathrm{M} \mathrm{HCl}$ belongs both physisorption and chemisorption.

Keywords: Synthesis; Structure; Corrosion; Steel; Hydrochloric acid.

\section{$\underline{\text { FULL TEXT }}$}

(C) 2019 The Authors. Published by ESG (www.electrochemsci.org). This article is an open access article distributed under the terms and conditions of the Creative Commons Attribution license (http://creativecommons.org/licenses/by/4.0/). 